\title{
Evaluation of a screening program for iron overload and HFE mutations in 50,493 blood donors
}

\author{
Carl Eckerström ${ }^{1,2}$ (I) Sofia Frändberg ${ }^{1} \cdot$ Lena Lyxe $^{1} \cdot$ Cecilia Pardi $^{1} \cdot$ Jan Konar $^{1}$ \\ Received: 16 January 2020 / Accepted: 14 June 2020 / Published online: 26 August 2020 \\ (C) The Author(s) 2020
}

\begin{abstract}
Early detection of individuals with hereditary hemochromatosis $(\mathrm{HH})$ is important to manage iron levels and prevent future organ damage. Although the HFE mutations that cause most cases of HH have been identified, their geographic distribution is highly variable, and their contribution to iron overload is not fully understood. All new registered blood donors at the Sahlgrenska University hospital between 1998 and 2015 were included in the study. Donors with signs of iron overload at baseline and subsequent follow-up testing were recommended genotyping of the HFE gene. Of the 50,493 donors that were included in the study, 950 (1.9\%) had signs of iron overload on both test occasions. Of the 840 donors with iron overload that performed HFE genotyping, 117 were homozygous for $\mathrm{C} 282 \mathrm{Y}$, and 97 were compound heterozygotes. The prevalence of $\mathrm{C} 282 \mathrm{Y}$ homozygosity was $0.23 \%$. Iron overload screening effectively detects individuals at risk of carrying the C282Y mutation of the HFE gene and enables early treatment to prevent $\mathrm{HH}$ complications.
\end{abstract}

Keywords Hereditary hemochromatosis $\cdot$ Screening program $\cdot$ Blood donors $\cdot$ HFE

\section{Introduction}

Hereditary hemochromatosis $(\mathrm{HH})$ is caused by mutations in the HFE gene, leading to a low production of hepcidin resulting in high uptake of iron from the intestine [1]. The subsequent iron-overload is often asymptomatic but may, left untreated, lead to liver cirrhosis, diabetes mellitus, hypothyroidism, cardiac arrhythmia and arthropathy [1]. The risk of developing sequelae is further increased by environmental factors such as excessive alcohol consumption and obesity [2].

Individuals homozygous for $\mathrm{C} 282 \mathrm{Y}$ make up only $0.4 \%$ of the population [3], but many of them will gradually accumulate iron and eventually develop symptoms of the disease. The overwhelming majority of patients with $\mathrm{HH}$ are either $\mathrm{C} 282 \mathrm{Y}$ homozygotes or $\mathrm{C} 282 \mathrm{Y} / \mathrm{H} 63 \mathrm{D}$ compound heterozygotes.

Carl Eckerström

carl.eckerstrom@neuro.gu.se

1 Department of Immunology and Transfusion medicine Region, Sahlgrenska University Hospital, Västra Götaland, Sweden

2 Institute of Neuroscience and Physiology, University of Gothenburg, Gothenburg, Sweden
Around $70 \%$ of $\mathrm{C} 282 \mathrm{Y}$ homozygotes have biochemical signs of iron overload, with levels between 73 and $94 \%$ reported in males and 55 and $69 \%$ in females [4-7]. However, it should be noted that these studies have used different cutoff levels for the definition of iron overload.

Early identification of individuals with $\mathrm{HH}$ is important, allowing for monitoring of iron levels and the application of therapeutic phlebotomy when needed to avoid further complications of the disease [8]. Presently, population screening for $H F E$ mutation is not recommended due to unfavourable cost-benefit ratio [3]. Evaluations of screening approaches where risk groups with iron-overload are identified for subsequent $H F E$ genotyping shows promising results $[9,10]$, but the variability in both prevalence and penetrance of $\mathrm{C} 282 \mathrm{Y}$ mutations together with the relative scarcity of large iron-overload screening studies highlights the need of further studies to assess the costbenefit of iron-overload screening for detection of individuals at risk of hereditary hemochromatosis.

Therefore, the aim of the study was to investigate the feasibility and usefulness of an iron-overload screening program to identify previously unknown $H F E \mathrm{C} 282 \mathrm{Y}$ and $\mathrm{H} 63 \mathrm{y}$ mutations in newly registered blood donors. We will also evaluate how using different cutoff levels will affect the ability of the screening program to identify HFE mutations. 


\section{Materials and methods}

The Sahlgrenska Iron Overload Study (SIOS) was started in 1998 with the aim of investigating causes and outcome of iron overload in blood donors. The study was approved by the local ethics committee in Gothenburg (approval number: 593-17; 170930).

All new registered blood donors between 1998 and 2015 that fulfilled criteria for blood donation and were not previously diagnosed with hereditary hemochromatosis or had known HFE mutations were included in the study. Eligibility for blood donation was established during the first visit using structured interview, checklists and blood sampling with subsequent analysis of s-Fe, s-total iron-binding capacity (TIBC) and s-ferritin. No blood was donated during the first visit. All donors that fulfilled our criteria for iron overload (transferrin saturation (TS) $>50 \%$ ) were selected for subsequent control measurement of TS\% and s-ferritin $(\mu \mathrm{g} / \mathrm{L})$. Based on the results from the control measurement, donors having TS $>50 \%$ or elevated s-ferritin (s-ferritin $>130$ for $\mathrm{men} / \mathrm{s}$-ferritin $>100$ for women) were recommended $H F E$ genotyping. In all, 50,493 blood donors were screened, and 2864 were found to have TS $>50 \%$. Of the donors with baseline TS $>50 \%, 74 \%$ (2131 donors) returned for control measurement with a mean time between baseline and control visit of 154 days. Control measurements were performed prior to blood donation. Of the 950 donors with elevated levels of TS or s-ferritin, 840 (88\%) were tested for the HFE C282Y and H63D mutations. Levels of s-Fe, s-TIBC and s-ferritin were determined using standard laboratory methods. Figure 1 illustrates the inclusion and testing procedure.

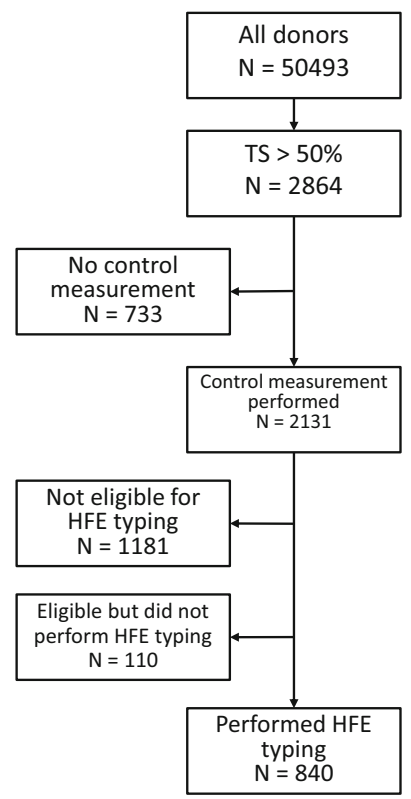

Fig. 1 The Sahlgrenska iron-overload study screening procedure

\section{Genetic analyses}

HFE C282Y and H63D were detected from EDTA wholeblood samples using ABI 7500 Real-Time PCR system (Applied Biosystems). Allele discrimination was performed using the ABI 7500 SDS software. Participants negative for C282Y and H63D were designated wild type.

\section{Statistical analyses}

Patients were grouped according to HFE status. Demographic differences were analysed using the unpaired $t$ test (age) and $\chi^{2}$ (sex). Levels of iron overload markers were compared between the groups with $\mathrm{C} 282 \mathrm{Y}$ or H63D alleles and the wild type group using the unpaired $t$ test. To evaluate diagnostic value for the identification of $\mathrm{C} 282 \mathrm{Y}$ homozygotes, we calculated sensitivity/specificity, positive/negative likelihood ratio and positive/negative predictive value of different levels of TS\% and s-ferritin using cross-tabulation. All analyses were performed using IBM SPSS software (version 19.0).

\section{Results}

As can be seen in Table 1, the largest group of donors with iron-overload did not have either the $\mathrm{C} 282 \mathrm{Y}$ or the H63D mutations. The majority were male irrespectively of HFE status, but the male dominance was least pronounced in the C282Y homozygous and C282Y/H63D compound heterozygous groups. These groups also have the most pronounced iron-overload compared with the wild type group.

Tables 2 and 3 shows participant characteristics divided by sex. Again, the $\mathrm{C} 282 \mathrm{Y}$ homozygotic group have the highest levels of iron deposits, but only males in the C282Y/H63D group have elevated iron levels compared with the wild-type group. The difference between the iron levels of the $\mathrm{C} 282 \mathrm{Y}$ homozygotic and C282Y/H63D compound heterozygotic groups and the wild type group is generally more pronounced in the follow-up testing.

A comparison between the SIOS participants that fulfilled the criteria for $H F E$ genotyping and the general population is displayed in Fig. 2. All groups carrying a mutation, with the exception for H63D/WT, were more prevalent in the SIOS group. The $\mathrm{C} 282 \mathrm{Y}$ homozygous and $\mathrm{C} 282 \mathrm{Y} / \mathrm{H} 63 \mathrm{D}$ compound heterozygous groups showed the highest overrepresentation compared with expected prevalence.

Table 4 displays a comparison of different TS\% cutoff values for the discovery of $\mathrm{C} 282$ homozygotes. Positive likelihood ratio increased with increasing cutoff levels in both men and women with the highest levels seen for s-ferritin > $350 \mu \mathrm{g} / \mathrm{L}$ in men and s-ferritin $>150 \mu \mathrm{g} / \mathrm{L}$ in women. Defining iron overload as TS $>50 \%$ and assuming $71 \%$ penetrance of iron overload in C282 homozygotes, we performed 
Table 1 Study participants

\begin{tabular}{lllllll}
\hline & C282/C282 & C282/H63 & H63/H63 & C282/WT & H63/WT & WT/WT \\
\hline$N$ & 117 & 97 & 31 & 125 & 131 & 339 \\
Age & $31.1 \pm 10.6$ & $29.1 \pm 10.6$ & $28.7 \pm 11.3$ & $28.6 \pm 9.8$ & $30.8 \pm 11.2$ & $29.1 \pm 9.0$ \\
Age range & $18-57$ & $18-56$ & $18-58$ & $18-60$ & $18-59$ & $18-62$ \\
Male sex \% & $62^{* *}$ & $75^{*}$ & 84 & 88 & 82 & 85 \\
TS baseline & $72.5 \pm 13.6^{* *}$ & $60.6 \pm 10.7^{* *}$ & $58.4 \pm 8.8$ & $57.1 \pm 7.4$ & $57.3 \pm 7.6$ & $57.1 \pm 7.4$ \\
TS F-U & $67.8 \pm 16.2^{* *}$ & $54.8 \pm 16.3^{* *}$ & $51.7 \pm 14.6^{*}$ & $48.7 \pm 14.5^{*}$ & $46.8 \pm 14.5$ & $44.5 \pm 15.1$ \\
S-ferritin & $383 \pm 334^{* *}$ & $204 \pm 186^{* *}$ & $170 \pm 119$ & $140 \pm 89$ & $161 \pm 106$ & $147 \pm 89$ \\
\hline
\end{tabular}

Groups carrying at least one allele of C282Y (C282) or H63D (H63) were compared with wild type donors. Values are given as mean value $\pm \mathrm{SD}$

$T S$ Transferrin saturation \%. F-U follow-up

$* P$ value $<0.05$ vs wild type. $* * P$ value $<0.001$ vs wild type

a cross tabulation on the entire cohort resulting in high specificity and positive likelihood ratios.

\section{Discussion}

The Sahlgrenska iron-overload study successfully screened 50,493 blood donors for iron-overload and was able to identify 117 donors that were homozygous for $\mathrm{C} 282 \mathrm{Y}$. The screening process considerably reduced the number of donors fulfilling the criteria for $H F E$ genotyping, resulting in 840 $(1.7 \%)$ donors ultimately genotyped. C282Y homozygotes and $\mathrm{C} 282 \mathrm{Y} / \mathrm{H} 63 \mathrm{D}$ compound heterozygotes were highly overrepresented in the group that was genotyped compared with previous reports on the prevalence of $\mathrm{C} 282 \mathrm{Y}$ and H63D alleles in the general population [11].

C282Y homozygotes made up $14 \%$ of the $1.7 \%$ of the cohort that performed HFE typing, indicating that the screening procedure produced a group with a high number of mutation carriers. The $117 \mathrm{C} 282 \mathrm{Y}$ homozygotes identified correspond to a prevalence of $0.23 \%$ in the screened cohort. Although the prevalence of $\mathrm{C} 282 \mathrm{Y}$ and $\mathrm{H} 63 \mathrm{D}$ alleles is highly variable across geographic regions in the world [12], studies on subjects with similar ancestry as ours have reported prevalence of $\mathrm{C} 282 \mathrm{Y}$ homozygotes between 0.30 and $0.75 \%$ [4-6, $11,13,14]$. Applying an iron-overload penetrance of $71 \%$ in homozygotes, [4-7], results in an estimation of 165 homozygotes in the cohort corresponding to a prevalence of $0.33 \%$

Table 2 Iron status and $H F E$ mutations for male participants

\begin{tabular}{|c|c|c|c|c|c|c|}
\hline & C282/C282 & C282/H63 & H63/H63 & C282/WT & H63/WT & WT/WT \\
\hline$N$ & 73 & 73 & 26 & 101 & 108 & 287 \\
\hline Age & $30.9 \pm 10.5$ & $28.9 \pm 10.3$ & $27.5 \pm 10.1$ & $27.7 \pm 8.6$ & $29.9 \pm 11.1$ & $28.7 \pm 8.8$ \\
\hline Age range & $18-57$ & $18-53$ & $18-57$ & $18-54$ & $18-59$ & $18-62$ \\
\hline \multicolumn{7}{|l|}{ Baseline } \\
\hline $\mathrm{S}-\mathrm{Fe}$ & $35.8 \pm 7.3^{* *}$ & $33.9 \pm 6.1^{*}$ & $33.3 \pm 6.7$ & $32.0 \pm 4.9$ & $33.1 \pm 5.4$ & $32.5 \pm 5.3$ \\
\hline S-TIBC & $47.1 \pm 5.5^{* *}$ & $55.6 \pm 6.2$ & $56.0 \pm 5.2$ & $55.8 \pm 6.4$ & $57.5 \pm 6.9$ & $57.0 \pm 6.7$ \\
\hline $\mathrm{TS}$ & $76.0 \pm 12.2^{* *}$ & $61.3 \pm 11.3^{* *}$ & $59.4 \pm 9.2$ & $57.4 \pm 7.8$ & $57.6 \pm 8.0$ & $56.9 \pm 7.7$ \\
\hline \multicolumn{7}{|l|}{ Follow-up } \\
\hline $\mathrm{S}-\mathrm{Fe}$ & $32.5 \pm 8.3^{* *}$ & $30.3 \pm 9.8^{* *}$ & $29.7 \pm 7.9^{*}$ & $26.9 \pm 8.1$ & $26.7 \pm 8.5$ & $25.1 \pm 9.1$ \\
\hline S-TIBC & $47.4 \pm 6.8^{* *}$ & $55.5 \pm 6.4^{*}$ & $57.1 \pm 5.8$ & $55.8 \pm 6.5$ & $58.0 \pm 7.0$ & $57.4 \pm 7.3$ \\
\hline $\mathrm{TS}$ & $69.1 \pm 16.5^{* * *}$ & $55.0 \pm 17.2^{* *}$ & $51.7 \pm 14.6^{*}$ & $48.4 \pm 13.8^{*}$ & $46.1 \pm 13.9$ & $43.9 \pm 15.0$ \\
\hline S-ferritin & $478 \pm 324^{* *}$ & $231 \pm 147^{* *}$ & $179 \pm 127$ & $150 \pm 88$ & $174 \pm 110$ & $159 \pm 90$ \\
\hline
\end{tabular}

Groups carrying at least one allele of C282Y (C282) or H63D (H63) were compared with wild type donors. Values are given as mean value \pm SD $S$-Fe Serum iron. S-TIBC serum total iron binding capacity. TS transferrin saturation \%. F-U follow-up. S-Fe and S-TIBC are reported as $\mu$ mol/L, Sferritin is reported as $\mu \mathrm{g} / \mathrm{L}$

$* P$ value $<0.05$ vs wild type. $* * P$ value $<0.001$ vs wild type 
Table 3 Iron status and HFE mutations for female participants

\begin{tabular}{|c|c|c|c|c|c|c|}
\hline & $\mathrm{C} 282 / \mathrm{C} 282$ & C282/H63 & H63/H63 & C282/WT & H63/WT & WT/WT \\
\hline$N$ & 44 & 24 & 5 & 24 & 23 & 52 \\
\hline Age & $31.4 \pm 11.0$ & $30.1 \pm 11.5$ & $35.0 \pm 16.2$ & $32.0 \pm 13.3$ & $35.5 \pm 10.8$ & $31.1 \pm 9.5$ \\
\hline Age range & $18-53$ & $18-56$ & $21-58$ & $18-60$ & $21-58$ & $19-51$ \\
\hline \multicolumn{7}{|l|}{ Baseline } \\
\hline $\mathrm{S}-\mathrm{Fe}$ & $32.9 \pm 7.5$ & $32.2 \pm 5.5$ & $31.2 \pm 3.9$ & $32.0 \pm 5.4$ & $32.8 \pm 6.4$ & $32.8 \pm 5.0$ \\
\hline S-TIBC & $49.6 \pm 8.6^{* *}$ & $55.3 \pm 6.0$ & $58.8 \pm 7.0$ & $57.2 \pm 7.8$ & $60.4 \pm 10.4$ & $57.0 \pm 8.6$ \\
\hline $\mathrm{TS}$ & $66.8 \pm 13.9^{* *}$ & $58.3 \pm 8.3$ & $53.0 \pm 1.6$ & $55.9 \pm 5.7$ & $56.3 \pm 5.5$ & $57.7 \pm 5.9$ \\
\hline \multicolumn{7}{|l|}{ Follow-up } \\
\hline $\mathrm{S}-\mathrm{Fe}$ & $31.4 \pm 7.5^{*}$ & $28.9 \pm 7.3$ & $31.6 \pm 15.1$ & $28.2 \pm 9.9$ & $29.4 \pm 10.6$ & $26.9 \pm 9.8$ \\
\hline S-TIBC & $48.2 \pm 6.9^{* *}$ & $52.3 \pm 7.9^{*}$ & $61.4 \pm 6.1$ & $57.0 \pm 7.0$ & $58.5 \pm 7.7$ & $56.8 \pm 9.1$ \\
\hline $\mathrm{TS}$ & $65.7 \pm 15.7^{* * *}$ & $54.2 \pm 13.5$ & $52.0 \pm 14.6$ & $49.8 \pm 17.6$ & $49.9 \pm 16.6$ & $47.6 \pm 15.4$ \\
\hline S-ferritin & $230 \pm 294^{* *}$ & $125 \pm 260$ & $124 \pm 55^{*}$ & $97 \pm 81$ & $102 \pm 57.3$ & $79 \pm 48$ \\
\hline
\end{tabular}

Groups carrying at least one allele of C282Y (C282) or H63D (H63) were compared with wild type donors. Values are given as mean value \pm SD $S$-Fe Serum iron. S-TIBC serum total iron-binding capacity. TS transferrin saturation \%. F-U follow-up. S-Fe and S-TIBC are reported as $\mu$ mol/L, Sferritin is reported as $\mu \mathrm{g} / \mathrm{L}$

$* P$ value $<0.05$ vs wild type. $* * P$ value $<0.001$ vs wild type

which is at the lower end of previously reported values. The estimated prevalence is likely too low, possibly reflecting a lower iron-overload penetrance in our young and healthy study population.

The levels of TS\% and s-ferritin differed between the groups that fulfilled the screening criteria. The highest levels were seen in the C282Y homozygotes and C282Y/H63D groups. Previous studies that have investigated iron levels and $H F E$ status in the population without applying screening criteria have found similar levels of TS\% and s-ferritin among C282Y homozygotes as we found in our screened group [4, 5, 11]. The other groups, however, have lower levels of TS\% and $\mathrm{s}$-ferritin in studies without screening criteria leading us to conclude that the applied conditions for eligibility for $H F E$ genotyping in the SIOS mainly discriminate donors with HFE mutations less strongly linked to hemochromatosis. Further support for this conclusion can be found when comparing the composition of the genotyped group in the SIOS compared with what has been reported in the general population (Fig. 2). The C282Y homozygous group (11.5\%) and the C282Y/H63D compound heterozygotic group (13.9\%) were highly prevalent in our iron-overload group compared to reported prevalence in the population $[4,5,11]$. Thus we conclude that the screening process was an efficient tool to select a group of individuals where relevant HFE mutations can be expected to be highly overrepresented.

Finding the correct cutoff value for inclusion into a screening program is fundamental. Similar screening studies have
Fig. 2 Prevalence of $H F E$ mutations in the SIOS cohort compared to the general population. ${ }^{1}$ Population prevalence based on findings in whites from the HEIRS study [11]. * $\chi^{2} P$ value $<0.05 . * * \chi^{2} P$ value $<0.001$

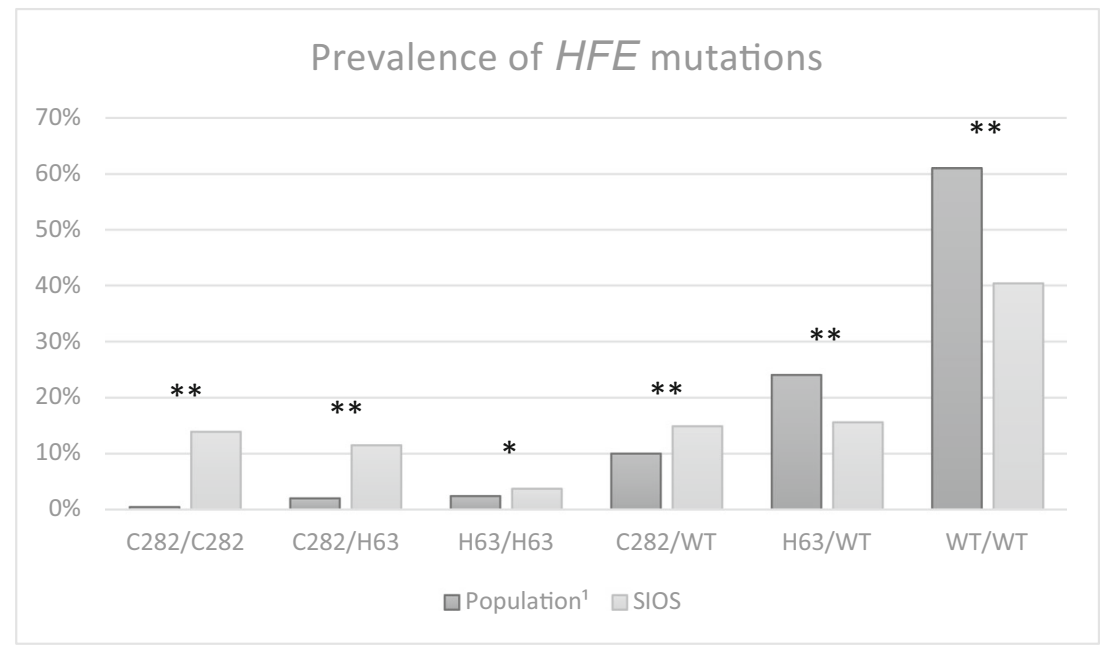


Table 4 Comparison of different TS\% cutoff values for the identification of $\mathrm{C} 282$ homozygotes

\begin{tabular}{|c|c|c|c|c|c|c|}
\hline & Sens. & Spec. & $+\mathrm{LR}$ & $-\mathrm{LR}$ & PPV & NPV \\
\hline \multicolumn{7}{|l|}{ Men } \\
\hline F-U TS $\%>50$ & 84 & 56 & $1.9(1.7-2.2)$ & $0.3(0.2-0.5)$ & $18(16-20)$ & 97 (95-98) \\
\hline F-U TS $\%>55$ & 76 & 70 & $2.5(2.1-3.0)$ & $0.3(0.2-0.5)$ & $22(19-26)$ & $96(94-98)$ \\
\hline F-U TS $\%>60$ & 71 & 80 & $3.5(2.8-4.4)$ & $0.4(0.3-0.5)$ & $29(24-34)$ & $96(94-97)$ \\
\hline F-U s-ferritin $>130$ & 93 & 36 & $1.5(1.3-1.6)$ & $0.2(0.1-0.5)$ & $15(14-16)$ & $98(95-99)$ \\
\hline F-U s-ferritin $>350$ & 63 & 94 & $10(7.2-14)$ & $0.4(0.3-0.5)$ & $56(47-64)$ & $96(94-97)$ \\
\hline \multicolumn{7}{|l|}{ Women } \\
\hline F-U TS $\%>50$ & 81 & 38 & $1.3(1.1-1.6)$ & $0.5(0.3-0.9)$ & $31(27-35)$ & $86(76-92)$ \\
\hline F-U TS $\%>55$ & 77 & 61 & $2.0(1.5-2.6)$ & $0.4(0.2-0.7)$ & $40(33-46)$ & 89 (81-93) \\
\hline F-U TS $\%>60$ & 60 & 76 & $2.5(1.7-3.7)$ & $0.5(0.4-0.8)$ & $46(37-56)$ & $85(79-89)$ \\
\hline F-U s-Ferritin $>100$ & 64 & 59 & $1.5(1.1-2.1)$ & $0.6(0.4-0.9)$ & $35(28-42)$ & $82(75-88)$ \\
\hline F-U s-Ferritin $>150$ & 41 & 88 & $3.4(1.9-6.2)$ & $0.7(0.5-0.9)$ & $55(40-68)$ & $81(40-68)$ \\
\hline \multicolumn{7}{|c|}{ Whole cohort assuming $71 \%$ penetrance of iron-overload in C282 homozygotes } \\
\hline Baseline TS $\%>50$ & 71 & 95 & $13(12-14)$ & $0.3(0.2-0.4)$ & $4.1(4-5)$ & $99(99-100)$ \\
\hline F-U TS $\%>50$ & 71 & 99 & $49(44-56)$ & $0.3(0.2-0.4)$ & $14(13-15)$ & $99(99-100)$ \\
\hline
\end{tabular}

$F-U$ Follow-up. Sens. sensitivity. Spec. specificity. $+L R$ positive likelihood ratio. $-L R$ negative likelihood ratio. $P P V$ positive predictive value. $N P V$ Negative predictive value employed varying cutoff levels, ranging between TS $>45$ and TS $>55 \%$. In retrospect, it would have been useful to have had a lower cutoff of TS $>45 \%$ in the SIOS to better evaluate the varying cutoff levels that have been used in previous studies, and also because recent findings have shown that TS $>45 \%$ may be the best cutoff point for identifying C282Y homozygotes [15], which is also reflected in recent recommendations [16]. Nonetheless, the screening method employed in the SIOS using TS $>50 \%$ yielded a group with high prevalence of C282Y homozygotes. When applying a $71 \%$ penetrance of iron-overload in C282Y homozygotes in the whole cohort, we found that the screening process resulted in high sensitivity and positive predictive values, especially so when applying a two-step approach with control measurements. However, there may be situations, such as in large population screening or where a low overall cost for the program is necessary, where a high positive predictive value is more important than a high sensitivity. In those situations, based on our findings, it may be advantageous to increase the follow-up TS cutoff to $55 \%$ in both men and women resulting in a substantial increase in specificity at the cost of a small reduction in sensitivity. It should be noted, however, that it may not be necessary to identify all $\mathrm{C} 282 \mathrm{Y}$ homozygotes as C282Y homozygotes without signs of iron overload seem to be at low risk of developing $\mathrm{HH}$ complications [17]. The trend towards increased HFE typing in individuals without biochemical signs of iron overload [18] highlights the need for the establishment of iron overload prior to genotyping for a more favourable cost-benefit ratio.

The contribution of mutations other than C282Y homozygotes to iron overload is not fully understood. Our findings that blood donors with iron overload are more likely to be
C282Y/H63D compound heterozygotes, C282Y heterozygotes or H63D homozygotes is in line with previous studies [19]. The relative low penetrance of these mutations on iron overload has not yet been determined, and the probable cause is genetic and environmental factors. Additionally, C282Y heterozygotes may carry rare mutations contributing to iron overload [20].

\section{Limitations}

Blood donors may not be representative for the general population. Although the majority of $H F E$ mutation carriers are asymptomatic and that the SIOS cohort is young (mean age 29.6) and may not have had time to develop symptoms, it is possible that signs of the disease may have discouraged some individuals from blood donation resulting in an underestimation of the prevalence of $H F E$ mutation carriers. Additionally, although blood donors are required to have a good command of Swedish and minorities are believed to be underrepresented as donors, we do not record ethnic origin of blood donors which could have affected the mutation frequencies. A limitation of the present study is also the lack of data for other mutations than $\mathrm{C} 282$ and H63. Although the C282 HFE mutation is the principal cause of $\mathrm{HH}$, other mutations may also give rise to iron overload [21]. Another issue with the study design is the lack of standardization of test setting. The blood for laboratory analyses were drawn when the participant registered to become a blood donor, which could have happened any time during the day. As circadian rhythms may potentially affect the results [22], it would have been preferable to standardize the blood collection reflecting this. 


\section{Conclusions}

Iron overload screening using TS\% effectively identifies a population with high prevalence of $\mathrm{C} 282 \mathrm{Y}$ and $\mathrm{H} 63 \mathrm{D}$ mutation carriers, enabling monitoring and early treatment to prevent $\mathrm{HH}$ complications.

Acknowledgements We would like to thank blood donors, staff and laboratory personnel at the department of immunology and transfusion medicine at Sahlgrenska University Hospital.

Authors' contributions Dr. Eckerström analysed the data and wrote the paper. Dr. Frändberg collected data for the study and revised the paper. Dr. Lyxe collected data for the study and revised the paper. Dr. Pardi collected data for the study and revised the paper. Dr. Konar designed the research study and revised the paper. All authors approved the final version of the paper.

Funding information Open access funding provided by University of Gothenburg. This work was financed by the Sahlgrenska University Hospital and by grants from the Swedish state under the agreement between the Swedish government and the county councils, the ALF agreement [Grant number ALFGBG-784831].

\section{Compliance with ethical standards}

Conflict of interest The authors declare that they have no conflict of interest.

Disclaimer The funding sources were not involved in the drafting of this manuscript.

Open Access This article is licensed under a Creative Commons Attribution 4.0 International License, which permits use, sharing, adaptation, distribution and reproduction in any medium or format, as long as you give appropriate credit to the original author(s) and the source, provide a link to the Creative Commons licence, and indicate if changes were made. The images or other third party material in this article are included in the article's Creative Commons licence, unless indicated otherwise in a credit line to the material. If material is not included in the article's Creative Commons licence and your intended use is not permitted by statutory regulation or exceeds the permitted use, you will need to obtain permission directly from the copyright holder. To view a copy of this licence, visit http://creativecommons.org/licenses/by/4.0/.

\section{References}

1. Salgia RJ, Brown K (2015) Diagnosis and management of hereditary hemochromatosis. Clin Liver Dis 19(1):187-198. https://doi. org/10.1016/j.cld.2014.09.011

2. Powell LW, Seckington RC, Deugnier Y (2016) Haemochromatosis. Lancet 388(10045):706-716. https://doi.org/ 10.1016/S0140-6736(15)01315-X

3. European Association For The Study Of The L (2010) EASL clinical practice guidelines for HFE hemochromatosis. J Hepatol 53(1): 3-22. https://doi.org/10.1016/j.jhep.2010.03.001

4. Allen KJ, Gurrin LC, Constantine CC, Osborne NJ, Delatycki MB, Nicoll AJ, McLaren CE, Bahlo M, Nisselle AE, Vulpe CD, Anderson GJ, Southey MC, Giles GG, English DR, Hopper JL, Olynyk JK, Powell LW, Gertig DM (2008) Iron-overload-related disease in HFE hereditary hemochromatosis. N Engl J Med 358(3): 221-230. https://doi.org/10.1056/NEJMoa073286

5. Pedersen P, Milman N (2009) Genetic screening for HFE hemochromatosis in 6,020 Danish men: penetrance of C282Y, H63D, and S65C variants. Ann Hematol 88(8):775-784. https://doi.org/ 10.1007/s00277-008-0679-1

6. Thorstensen K, Kvitland MA, Irgens WO, Hveem K, Asberg A (2010) Screening for C282Y homozygosity in a Norwegian population (HUNT2): the sensitivity and specificity of transferrin saturation. Scand J Clin Lab Invest 70(2):92-97. https://doi.org/10. 3109/00365510903527838

7. Deugnier Y, Jouanolle AM, Chaperon J, Moirand R, Pithois C, Meyer JF, Pouchard M, Lafraise B, Brigand A, CaserioSchoenemann C, Mosser J, Adams P, Le Gall JY, David V (2002) Gender-specific phenotypic expression and screening strategies in C282Y-linked haemochromatosis: a study of 9396 French people. Br J Haematol 118(4):1170-1178. https://doi.org/10.1046/ j.1365-2141.2002.03718.x

8. Aleman S, Endalib S, Stal P, Loof L, Lindgren S, Sandberg-Gertzen H, Almer S, Olsson S, Danielsson A, Wallerstedt S, Hultcrantz R (2011) Health check-ups and family screening allow detection of hereditary hemochromatosis with less advanced liver fibrosis and survival comparable with the general population. Scand J Gastroenterol 46(9):1118-1126. https://doi.org/10.3109/ 00365521.2011 .591426

9. Asberg A, Hveem K, Thorstensen K, Ellekjter E, Kannelonning K, Fjosne U, Halvorsen TB, Smethurst HB, Sagen E, Bjerve KS (2001) Screening for hemochromatosis: high prevalence and low morbidity in an unselected population of 65,238 persons. Scand $\mathrm{J}$ Gastroenterol 36(10):1108-1115

10. de Graaff B, Neil A, Si L, Yee KC, Sanderson K, Gurrin L, Palmer AJ (2017) Cost-effectiveness of different population screening strategies for hereditary haemochromatosis in Australia. Appl Health Econ Health Policy 15(4):521-534. https://doi.org/10. 1007/s40258-016-0297-3

11. Barton JC, Acton RT, Lovato L, Speechley MR, CE ML, Harris EL, Reboussin DM, Adams PC, Dawkins FW, Gordeuk VR, Walker AP, Hemochromatosis, Iron Overload Screening Study Research I (2006) Initial screening transferrin saturation values, serum ferritin concentrations, and HFE genotypes in native Americans and whites in the hemochromatosis and iron overload screening study. Clin Genet 69(1):48-57. https://doi.org/10.1111/j. 1399-0004.2006.00553.x

12. Merryweather-Clarke AT, Pointon JJ, Jouanolle AM, Rochette J, Robson KJ (2000) Geography of HFE C282Y and H63D mutations. Genet Test 4(2):183-198. https://doi.org/10.1089/ 10906570050114902

13. Steinberg KK, Cogswell ME, Chang JC, Caudill SP, McQuillan GM, Bowman BA, Grummer-Strawn LM, Sampson EJ, Khoury MJ, Gallagher ML (2001) Prevalence of C282Y and H63D mutations in the hemochromatosis (HFE) gene in the United States. JAMA 285(17):2216-2222. https://doi.org/10.1001/jama.285.17. 2216

14. Jackson HA, Carter K, Darke C, Guttridge MG, Ravine D, Hutton RD, Napier JA, Worwood M (2001) HFE mutations, iron deficiency and overload in 10,500 blood donors. Br J Haematol 114(2): 474-484. https://doi.org/10.1046/j.1365-2141.2001.02949.x

15. O'Toole R, Romeril K, Bromhead C (2017) Using iron studies to predict HFE mutations in New Zealand: implications for laboratory testing. Intern Med J 47(4):447-454. https://doi.org/10.1111/imj. 13360

16. Adams P, Altes A, Brissot P, Butzeck B, Cabantchik I, Cancado R, Distante S, Evans P, Evans R, Ganz T, Girelli D, Hultcrantz R, McLaren G, Marris B, Milman N, Nemeth E, Nielsen P, Pineau B, Piperno A, Porto G, Prince D, Ryan J, Sanchez M, Santos P, Swinkels D, Teixeira E, Toska K, Vanclooster A, White D, 
Contributors, Hemochromatosis International T (2018) Therapeutic recommendations in HFE hemochromatosis for p.Cys282Tyr (C282Y/C282Y) homozygous genotype. Hepatol Int 12(2):83-86. https://doi.org/10.1007/s12072-018-9855-0

17. Allen KJ, Bertalli NA, Osborne NJ, Constantine CC, Delatycki MB, Nisselle AE, Nicoll AJ, Gertig DM, CE ML, Giles GG, Hopper JL, Anderson GJ, Olynyk JK, Powell LW, Gurrin LC, HealthIron Study I (2010) HFE Cys282Tyr homozygotes with serum ferritin concentrations below $1000 \mathrm{microg} / \mathrm{L}$ are at low risk of hemochromatosis. Hepatology 52(3):925-933. https://doi.org/10. 1002/hep.23786

18. Lanktree MB, Lanktree BB, Pare G, Waye JS, Sadikovic B, Crowther MA (2015) Examining the clinical use of hemochromatosis genetic testing. Can J Gastroenterol Hepatol 29(1):41-45

19. Burke W, Imperatore G, McDonnell SM, Baron RC, Khoury MJ (2000) Contribution of different HFE genotypes to iron overload disease: a pooled analysis. Genet Med 2(5):271-277. https://doi. org/10.1097/00125817-200009000-00001
20. Aguilar-Martinez P, Grandchamp B, Cunat S, Cadet E, Blanc F, Nourrit M, Lassoued K, Schved JF, Rochette J (2011) Iron overload in HFE C282Y heterozygotes at first genetic testing: a strategy for identifying rare HFE variants. Haematologica 96(4):507-514. https://doi.org/10.3324/haematol.2010.029751

21. Laursen AH, Bjerrum OW, Friis-Hansen L, Hansen TO, Marott JL, Magnussen K (2018) Causes of iron overload in blood donors - a clinical study. Vox Sang 113(2):110-119. https://doi.org/10.1111/ vox.12619

22. Guillygomarc'h A, Christian J, Romain M, Vincent Q, Veronique D, Deugnier Y (2003) Circadian variations of transferrin saturation levels in iron-overloaded patients: implications for the screening of C282Y-linked haemochromatosis. Br J Haematol 120(2):359-363. https://doi.org/10.1046/j.1365-2141.2003.04070.x

Publisher's note Springer Nature remains neutral with regard to jurisdictional claims in published maps and institutional affiliations. 